\title{
The Impact of Negative Online Review on Consumer's Purchase Intention: A Dual-Process Perspective
}

\author{
Quan Xiao \\ School of Information Technology, Jiangxi University of Finance and Economics, \\ 330032 Nanchang, China, \\ xiaoquan@foxmail.com
}

\begin{abstract}
Online review is an important reference for online consumer's purchase decision, among which the effect of negative online review is even greater. However, there is still a lack of attention on the impact of negative online review compared to positive one. Drawing on the dual-process theory, this study develops a research model to examine important factors affecting consumer's purchase intention, mainly focusing on negative online review. An online survey involving users of online shopping websites such as JD.com, Taobao.com and Amazon.cn is conducted to empirically test the proposed research model. The result shows that quality of negative review, as a systematic/central factor, is the primary factor affecting consumer's purchase intention, while heuristic/peripheral factors such as source credibility andquantity of negative review are also evaluated by consumer when making purchase decision.It is also examined that quality of negative review has a stronger impact on purchase intention when the consumer has a high self-efficacy level. Finally we discuss the theoretical and practical implications based on the findings.
\end{abstract}

Keywords: negative online review; consumer's purchase intention; dual-process theory

\section{Introduction}

Word-of-mouth(WOM) is defined as "an interpersonal communication, about an organization or its products that is independent from the organization's marketing activities"[1]. Online review is a new form of WOM communicated via Internet, which has beenextended to include far-ranging social communications mediated by information technology [2]. As online reviews contain rich information about attributes and qualities of products experienced by consumers themselves, it is able to lower the uncertainty of product information and risk of purchasing [3]. Online review is becominginfluential in both guiding consumer decisions [4-5] and marketing for online merchants [6-7].

In online review systems, reviewers are usually required to rate for the contents or products to be evaluated (e.g., one star is extremely negative, five star is extremely positive and three star for neutral) [8]. A number of prior studies posit that negative review is much more influential than positive one [9-10], and consumers tend to make decisions relying on negative review ${ }^{1}[11]$. However, compared to positive review, negative reviewis not well studied yet. Extant literatures on negative review mainly focus on the antecedences, impact ofvalence on its usefulness, and consumer's decision compared with positive review. There is a general lack of theoretical research on how negative review influence consumer's purchase intention and what factors moderate the influence. Because negative review can generate negative impact on consumer's purchase

1 All concepts of review in this study refers to online review. 
intention, which further affects performance of online merchants, to investigate the impact of negative review on consumer's purchase intention is beneficial to better administration of negative review for online merchants and can provide foundation for marketing.

This work investigates the antecedents of online consumer's purchase intention in the context of negative review from a dual-process perspective, and we try to answer two key questions: 1) what are the systematic/central and heuristic/peripheral factors of negative review adopted for consumer's purchase intention?, and 2) how do these factors influence consumers at different level of self-efficacy? This workattempts to make contributions to both literatures on impact of negative review and provide implications for practitioners.

\section{Literature Review}

\subsection{Online Review and its Impact}

Literatures on online review can be classified into three levels: market level, individual level and technical level. Researches on market level mainly focus on whether review characteristics can affect market outcomes (e.g., product sales, revenues and even share price) [7-13], while researches on individual level concern consumer's motivation to post online review and impact of online review on individual's decision-making [8-14]. Researches on technical level investigates techniques and methods for processing online review data, such as text mining, classification, automatic identification and so on [15-16]. This work falls onto the individual level and it is expected to find out how negative review may affect consumer's purchase intention.

According to information acceptance model, the characteristics of online review determine its usefulness, which further affects consumer's purchase intention. So the usefulness of online view has been a hot topic foronline review researches, which attemptsto answer questions such as "which review is more useful"[12] and "review posted by whom is more useful" [17], etc. For the first question, the content attributes are usually studied, including valence, words and expressions, length, extremeness, etc. [12-19].Researches answering the second question are relatively fewer in number, which concern the source attributes of online review [17]. Nayloret al. [20] verified that similarity between reviewer and reader would positively influence the perceived usefulness of review. Factors such as the expert role, knowledge level and activeness would also be influential [21-22]. Previously proposed influential factors and characteristics of online review need to be considered and sifted in this work, due to their direct or indirect effects on consumer's purchase intention.

\subsection{Negative Online Review}

Online review consists of positive, negative, and neutral ones. Positive review motivates consumer's purchase behavior, while negative review commonly has negative impact on consumer's purchase decision [23]. Positive reviews are usually superiorin quantity, however, as Chang's opinion [24], negative information has a greater and diagnostic effect on consumer purchase decisions than is the case with positive information, and negative review may exert stronger effects than positive onedue to the asymmetric effects [18].

Generally, literatures on negative review mainly focus on two issues. 1) Motivations and reasons for consumersposting negative review: from the perspective of motivations, to post negative review may enable reviewers appeared to be intelligent and professional, and some reviewers can vent through criticism, so the motivations for posting negative reviews may be stronger [25-26]. 2)The positive/negative valence of online review: for example, Godes \& Silva [27] and Moe [28] found downtrend of online review's valence over time. Actually, consistent conclusions have not been drawn yet about theeffects of reviewswith different valences. From the viewpoint of trust, Zhao [29] proposed that if 
online reviewto be toopositive, consumers might doubt its authenticity thereby lowered its usefulness. Mudambi [12] discovered that neutral online review could provide more objective information thus be more useful. Overall, few studies examined the influence of interaction between consumers and companies on negative review [30].

It is rather difficult to cope with negative review. As the transmission of negative review is often anonymous, with both truth and rumor confused, literatures on negative review are much fewer in number than positive review, and some researches restricted the analysis on positive online reviews to achieve simple designs [13].In spite of this, the impact of negative review on consumer's purchase decision and further online merchant's marketing is undoubtedlynonnegligible, hence, it is necessary to make clear the influencing mechanism of negative review to consumer's purchase intention.

\subsection{Dual-Process Model}

During consumer processing online review, useful information can change one's attitude by persuasiveness, and conduct the purchase behavior to turn into sales. Dual-process theory is a valid framework in explaining the impacts of online reviews at the individual leve 1[8]. Heuristic-systematic model (HSM) [31] and elaboration likelihood model (ELM) [32] are two prevalent dual-process models and have been widely adopted in the information persuasiveness of electronic WOM. In dual-process theory, the modes that people process information, establish validity assessments and later form decision outcomes are comprehensively investigated [33]. The mechanisms of HSM and ELM are similar. HSM posits that individual processes information in systematic way or heuristic way, while ELM indicates that the individual's attitude can be persuaded through two routes: central route and peripheral route.In systematic way and central route, high cognitive effort is made to elaborate information, while in heuristic way and peripheral route, heuristic and simple decision rules are adopted [34].

In the extant literatures, Park et. al., [35] examined that the quality (central route) and quantity (peripheral route) of online reviews positively affect consumers' decisions.Zhang [36] presented that argument quality (systematic way) and source credibility (heuristic way) can influence the adoption of online reviews in online communities.Thompson [37] found that for consumers rich in cognitive resources, perceived information expertise is main factor affecting their attitude while for consumers lacking of cognitive resources perceived similarity with review is the main factor.Despite widely adopted in EC and IS fields, dual-process theory have not been investigated in depth aiming at negative review. In the context of negative review, questions such as "what factors are systematic/central", "which are heuristic/ peripheral", "what is the moderator between negative review and purchase intention", are still not clear in extant studies. We attempt to provide insights into these issues.

\section{Theoretical Foundation and Model}

\subsection{Systematic/Central Factor}

According to dual-process theory, systematic way in HSM or central route in ELM refers that "people consider all relevant pieces of information, elaborate on these pieces of information, and form a judgment based on these elaborations" [38]. If people have sufficient motivation, ability, and cognitive resources, they tend to choose systematic processing way or central route to process information [39]. In applications of dual-process theory, argument quality has been consistently identified as a systematic/central factor in persuasion process [40-41]. Argument quality refers to "the audience's subjective perception of the arguments in the persuasive message as strong and cogent on the one hand versus weak and specious on the other" [42]. Sussman [43] posited information quality to be an important antecedent of knowledge adoption in 
organizations. It has also been shown that informative advertisements can lead to purchase behavior[44]. Therefore in the contrast, we expect that if a consumer finds the quality of negative review about a product to be stronger, the consumer's purchase intention may be lower. The following hypothesis is provided:

\section{H1. Quality of negative review negatively affects consumer's purchase intention.}

\subsection{Heuristic/Peripheral Factor}

In dual-process theory, heuristic way in HSM and peripheral route in ELM mean that "people consider a few informational cues, or even a single informational cue" to form a judgment [45]. If the motivations, abilities, and cognitive resources of an information recipient are low, then he tends to process information in heuristic way or peripheral route [39]. As people are commonly economy-minded, heuristic way or peripheral route, which are contextually oriented towards the communication environment,might be default strategies in information processing due to the least effort principle [46]. In our work, we refer source credibility and quantity of negative reviews as main heuristic/peripheral factors.

\section{(1) Source Credibility}

Source credibility refers to a recipient's perception of the credibility of an information source [31], which is considered as an importantperipheral cue in the informational influence process [43-47]. Although source credibility doesn't concern with the information content itself, it can play an important role in affecting consumer's purchase intention.As source credibility captures the perceived expertise and trustworthiness of review sources [47], it is plausible to infer that consumers will be more unlikely to purchase a product if the negative review is posted from a reputable source. The following hypothesis is expected:

\section{H2. Source credibility of negativereviewnegatively affects consumer's purchase intention.}

(2) Quantity of negative review

When a consumer browsing products on an online shopping website, the quantity or proportion of negative review is an important cue to be concerned. As the concerning of "quantity of negative review" is not the substantial content of negative review, it is deemed as heuristic cue by principle. Referring to previous studies, we define quantity of negative review as consumer's perception regarding the volume or proportion of negative review. Park [48] and Sher [49] considered quantity of review as effective decision rule that helps consumer forming quick decision. Thus, we can expect that a consumer is more unlikely to purchase a given product if he perceives a high quantity of negative review, and the hypothesis can be drawn as:

\section{H3. Quantity of negative review negatively affects consumer's purchase intention.}

\subsection{Moderating Role of Self-Efficacy}

According to ELM, individual's ability moderates his elaboration of information. If the individual's ability is relatively low, the peripheral route plays a role, andif the individual's ability is high, he will process information through central route $[43,50]$. Therefore, we bring forward the construct of self-efficacy to explore the moderating role of individual's ability. Self-efficacy refers to the perceived ability when individual performs activities to accomplish a desired task [51]. In the context of negative review, self-efficacymeans the consumer's perceived ability of collecting, analyzing and using of information related to the negative review about a product. 
As Marakas et. al.,[51] argued, self-efficacy should be a multidimensional construct to be measured effectively. In general, the perceived self-efficacy will be higher if the individual's expertise is stronger and the extent of involvement is higher. Thus, we propose two dimensions of self-efficacy: expertise and involvement. We refer to expertise as the consumer's prior knowledge about the product and the negative review while involvement represents the personal relevance of the product and the review. Usually, individual with higher expertise and involvement will pay more attention on the content of information itself, so when facing with negative review, the consumer will perceive higher ability for analyzing and using information contained in the review, and then he will tend to choose central route to form decision via the quality of review due to his high self-efficacy. On the contrast, if the consumer's ability for processing negative review on product is insufficient, he will not be able to process the substantial content of negative review, but to concern on other factors such as reviewer, quantity of negative review, etc., due to the low self-efficacy, thus the peripheral route will inclined to be adopted to form judgment [34].

Based on analysis of moderating effects above, the following hypotheses are provided:

H4: The negative effect of quality of negative review on purchase intention will be stronger for consumers with higher self-efficacy.

H5: The negative effect of source credibility of negative review on purchase intention will be stronger for consumers with lower self-efficacy.

H6: The negative effect of quantity of negative review on purchase intention will be stronger for consumers with lower self-efficacy.

Figure 1 depicts the research model of this study.

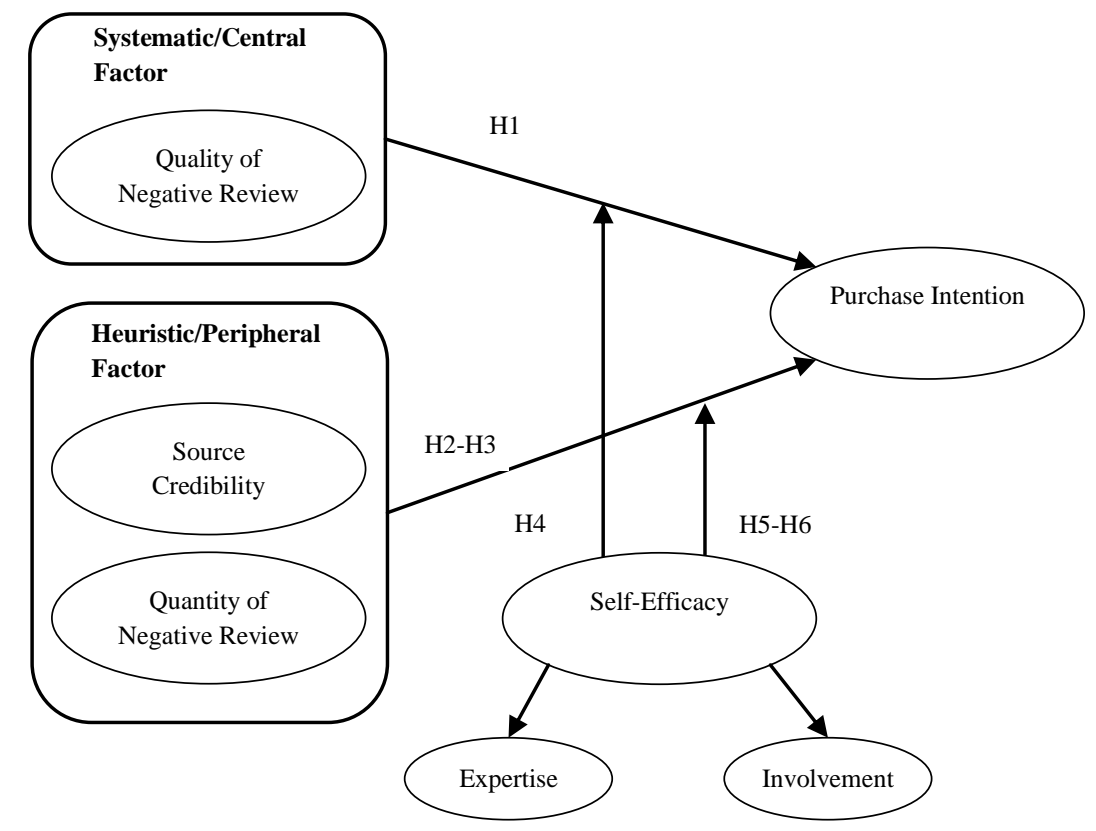

Figure 1. Research Model

\section{Methodology}

\subsection{Questionnaire Development}

To examine the proposed research model, we developed an online survey questionnaire. Consumers who recently purchased products via online shopping websites 
such as JD.com, Taobao.com and Amazon.cn in the past three months were invited. The survey instructions required each respondent to recall the most recent negative review he had read on the online shopping website about the product he was interested in, and then to complete the online survey questionnaire based on his perceptionsat the time. The questionnaire was developed by adopting previously validated measures in the literatures, including quality of negative review [13-52], source credibility [13-53], expertise [43], involvement [54], purchase intention [55] and we develop measures for quantity of negative review. The survey took about 10 minutes to complete.All items used 7-point Likert scales (from strongly disagree to strongly agree). Some wordings of the items were slightly modified to adapt the negative review context. The measurement of constructs for the research is depicted in Appendix A.

\subsection{Data Collection}

We distributed hyperlink of the questionnaire among potential eligible respondents. After a month of questionnaire distribution and collection, totally 228 recipients responded to the survey. After discarding invalid responses, 201 responses were included in the data analysis. Table 1, shows the demographic characteristics of the sample.

Table 1. Demographic Characteristics

\begin{tabular}{llll}
\hline & & Number & Frequency \\
\hline Gender & Male & 89 & $44.3 \%$ \\
Age & Female & 112 & $55.7 \%$ \\
& $<22$ & 13 & $6.47 \%$ \\
& $22-26$ & 109 & $54.23 \%$ \\
Education & $27-31$ & 55 & $27.36 \%$ \\
& $>31$ & 24 & $11.94 \%$ \\
\multirow{3}{*}{ Annual Income } & High school or below & 20 & $10.0 \%$ \\
& University & 148 & $73.6 \%$ \\
& Postgraduate or above & 33 & $16.4 \%$ \\
& $<20000$ & 13 & $6.5 \%$ \\
& $20001-60000$ & 94 & $46.8 \%$ \\
& $60001-100000$ & 71 & $35.3 \%$ \\
\hline
\end{tabular}

As shown in Table 1, 55.7 percent of all respondents were female and 44.3 percent were male. 81.59 percent of participants were aged from22to31, 93.5\% had incomes of above 20000 RMB per year.90.0\% had university or above degrees.

\section{Data Analysis}

\subsection{Measurement Model}

SPSS 22.0 is employed to perform reliability analysis for the collected data, and AMOS 22.0 is employed to perform confirmatory factor analysis to assess the validity of the constructs. Table 2 listed the values ofCronbach's Alpha, factor loading, Average Variance Extracted (AVE) and Composite Reliability (CR). As shown in Table 2, Cronbach's Alphas of all constructs are above 0.8 with significance $\mathrm{p}<0.001$.The CR values of all constructs range from 0.844 to 0.903 , which are above the recommended benchmark of 0.7. The AVE values of all constructs ranged from 0.660 to 0.729 , which are above the recommended level of 0.5 . It indicatesthe measurement model's convergent validity to be satisfactory.

Table 2. Measurement Validity Assessment

\begin{tabular}{llllll}
\hline Construct & Item ID & Factor Loading & Cronbach's $\alpha$ & AVE & CR
\end{tabular}




\begin{tabular}{|c|c|c|c|c|c|}
\hline \multirow{2}{*}{$\begin{array}{l}\text { Quality of Negative Reviews } \\
\text { (QLNR) }\end{array}$} & QLNR1 & 0.777 & 0.886 & 0.660 & 0.886 \\
\hline & QLNR2 & 0.833 & \multirow{7}{*}{0.901} & \multirow{7}{*}{0.700} & \multirow{7}{*}{0.903} \\
\hline \multirow{6}{*}{$\begin{array}{l}\text { Source Credibility } \\
\text { (SC) }\end{array}$} & QLNR3 & 0.830 & & & \\
\hline & QLNR4 & 0.808 & & & \\
\hline & SC1 & 0.809 & & & \\
\hline & $\mathrm{SC} 2$ & 0.861 & & & \\
\hline & SC3 & 0.794 & & & \\
\hline & $\mathrm{SC} 4$ & 0.879 & & & \\
\hline \multirow{6}{*}{$\begin{array}{l}\text { Quantity } \\
\text { Reviews } \\
\text { (QTNR) } \\
\text { Expertise } \\
\text { (EXP) }\end{array}$} & QTNR1 & 0.807 & \multirow[t]{3}{*}{0.843} & \multirow[t]{3}{*}{0.643} & \multirow[t]{3}{*}{0.844} \\
\hline & QTNR2 & 0.786 & & & \\
\hline & QTNR3 & 0.812 & & & \\
\hline & EXP1 & 0.813 & \multirow[t]{3}{*}{0.853} & \multirow[t]{3}{*}{0.661} & \multirow[t]{3}{*}{0.854} \\
\hline & EXP2 & 0.829 & & & \\
\hline & EXP3 & 0.797 & & & \\
\hline \multirow{3}{*}{$\begin{array}{l}\text { Involvement } \\
\text { (INV) }\end{array}$} & INV1 & 0.834 & \multirow[t]{3}{*}{0.863} & \multirow[t]{3}{*}{0.677} & \multirow[t]{3}{*}{0.863} \\
\hline & INV2 & 0.820 & & & \\
\hline & INV3 & 0.815 & & & \\
\hline \multirow{3}{*}{$\begin{array}{l}\text { Purchase Intention } \\
\text { (PI) }\end{array}$} & PI1 & 0.860 & \multirow[t]{3}{*}{0.894} & \multirow[t]{3}{*}{0.729} & \multirow[t]{3}{*}{0.895} \\
\hline & $\mathrm{PI} 2$ & 0.827 & & & \\
\hline & PI3 & 0.891 & & & \\
\hline
\end{tabular}

To examine the discriminant validity of the measurement model, we can compare the square root of the AVE values of constructs with the correlations between them. Table 3 shows the result of discriminant validity test. The square root of the AVE value for each construct is above the correlation between the construct and other constructs, which means the discriminant validity of the measurement model to be satisfactory.

Table 3. Result of Discriminant Validity tTst

\begin{tabular}{lllllll}
\hline & QLNR & SC & QTNR & EXP & INV & PI \\
\hline QLNR & $\mathbf{0 . 8 1 2}$ & & & & & \\
SC & 0.674 & $\mathbf{0 . 8 3 4}$ & & & & \\
QTNR & 0.282 & 0.448 & $\mathbf{0 . 8 0 2}$ & & & \\
EXP & 0.448 & 0.398 & 0.301 & $\mathbf{0 . 8 1 3}$ & $\mathbf{0 . 8 2 3}$ & \\
INV & 0.376 & 0.383 & 0.263 & 0.765 & -0.455 & $\mathbf{0 . 8 5 4}$ \\
PI & -0.648 & -0.649 & -0.563 & -0.469 & & \\
\hline
\end{tabular}

The value in the diagonal line of the table is the square root of AVE.

We utilize variance inflation factor (VIF) to evaluate the potential issue of multi-collinearity between different constructs.According the results in SPSS 22.0, the VIFs of constructs range from 1.286 to 2.631 , which are all below the benchmark of 10 , suggesting that the multi-collinearity does not seriously threaten theanalysis.

\subsection{Hierarchy Regression Analysis}

Hierarchy regression analysis is employed to test the proposed hypotheses. Table 4 depicts the result of hierarchy regression analysis with consumer's purchase intention as dependent variable. Model 1 examines the influence of all independent variable on purchase intention (H1-H3). In Model 2, self-efficacy is introduced based on Model 1. On the basis of Model 2, Model 3a-3c adds an interaction item between self-efficacy and one independent variable (QLNR, SC, QTNR) respectively to reflect the moderate role of self-efficacy (H4-H5).All independent and moderating variablesare mean-centered beforeproducing the interaction terms to minimize potential multi-collinearity.

Table 4. Result of Hierarchy Regression Analysis

\begin{tabular}{llllll}
\hline & Model 1 & Model 2 & Model 3a & Model 3b & Model 3c \\
\hline Block 1: & & & & & \\
Main effect & & & & \\
QLNR & $-0.398 * * *$ & $-0.352 * * *$ & $-0.349 * * *$ & $-0.364 * * *$ & $-0.350^{* * * *}$ \\
SC & $-0.223 * *$ & $-0.200 * *$ & $-0.182 * *$ & $-0.199 * *$ & $-0.198 * *$ \\
\hline
\end{tabular}




\begin{tabular}{llllll}
\hline QTNR & $-0.351 * * *$ & $-0.327 * * *$ & $-0.343 * * *$ & $-0.319 * * *$ & $-0.321 * * *$ \\
SE & & $-0.155^{* *}$ & $-0.173^{* * *}$ & $-0.145^{* * *}$ & $-0.145^{* * *}$ \\
Block 2: & & & & \\
Moderating effect & & & & \\
QLNR*SE & & $-0.129 * *$ & & \\
SC*SE & & & $0.093 *$ & \\
QTNR*SE & & & & $0.124 * *$ \\
Adjusted R2 & 0.594 & 0.610 & 0.625 & 0.617 & 0.624 \\
F value & 98.477 & 79.324 & 67.613 & 65.427 & 67.363 \\
\hline
\end{tabular}

Note: $* \mathrm{p}<0.05 ; * * \mathrm{p}<0.01 ; * * * \mathrm{p}<0.001$.

Model 1 suggests that all dependent variables have significantly negative impacts on PI, among which the QLNR generates the greatest impact $(b=-0.398, p<0.001)$. In Model $3 \mathrm{a}$, positive moderating effect of SE on the relationship between QLNR and PI is observed $(b=0.093, p<0.05)$. From Model $3 b$, it is identified that SE negatively moderates the relationship between SC and PI $(b=0.093, p<0.05)$. Model $3 \mathrm{c}$ shows a significantly negative moderating role of SE on the relationship between QTNR and PI ( $b=0.124$, $\mathrm{p}<0.01$ ). Thus, all hypotheses for the main and moderating effects are supported.

As self-efficacy has different moderating effects on the relationship between systematic/central factor or heuristic/peripheral factors and consumer's purchase intention. The two-wayinteraction graphs for the interaction effects aredisplayed in Figure $2-4$.

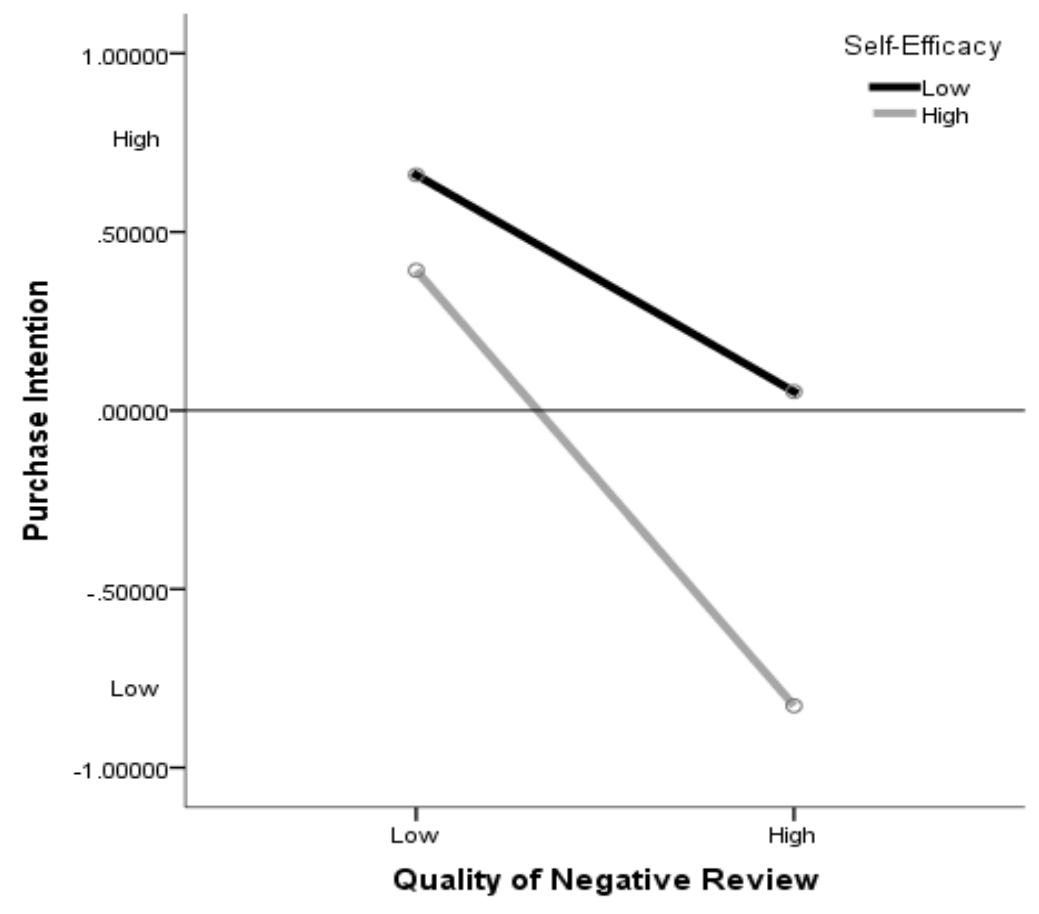

Figure 2. Purchase Intention Impact of Quality of Negative Review 


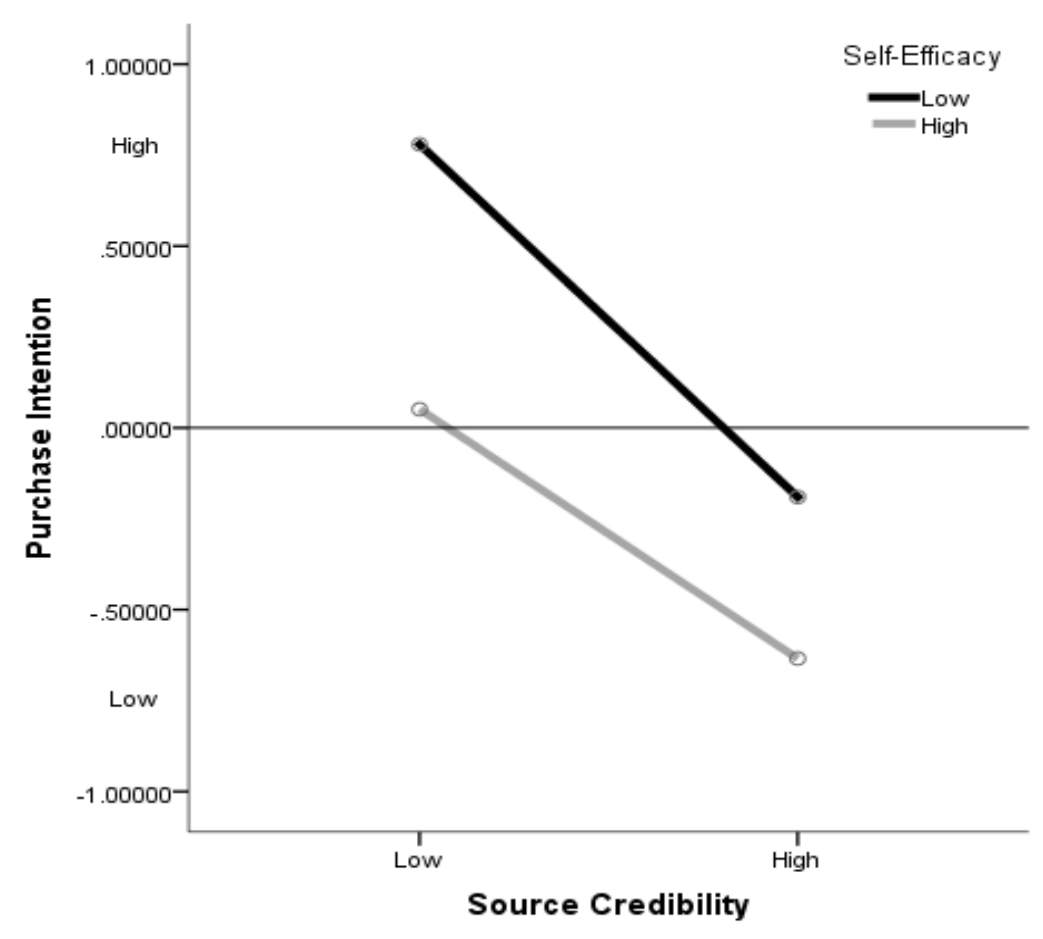

Figure 3. Purchase Intention Impact of Source Credibility

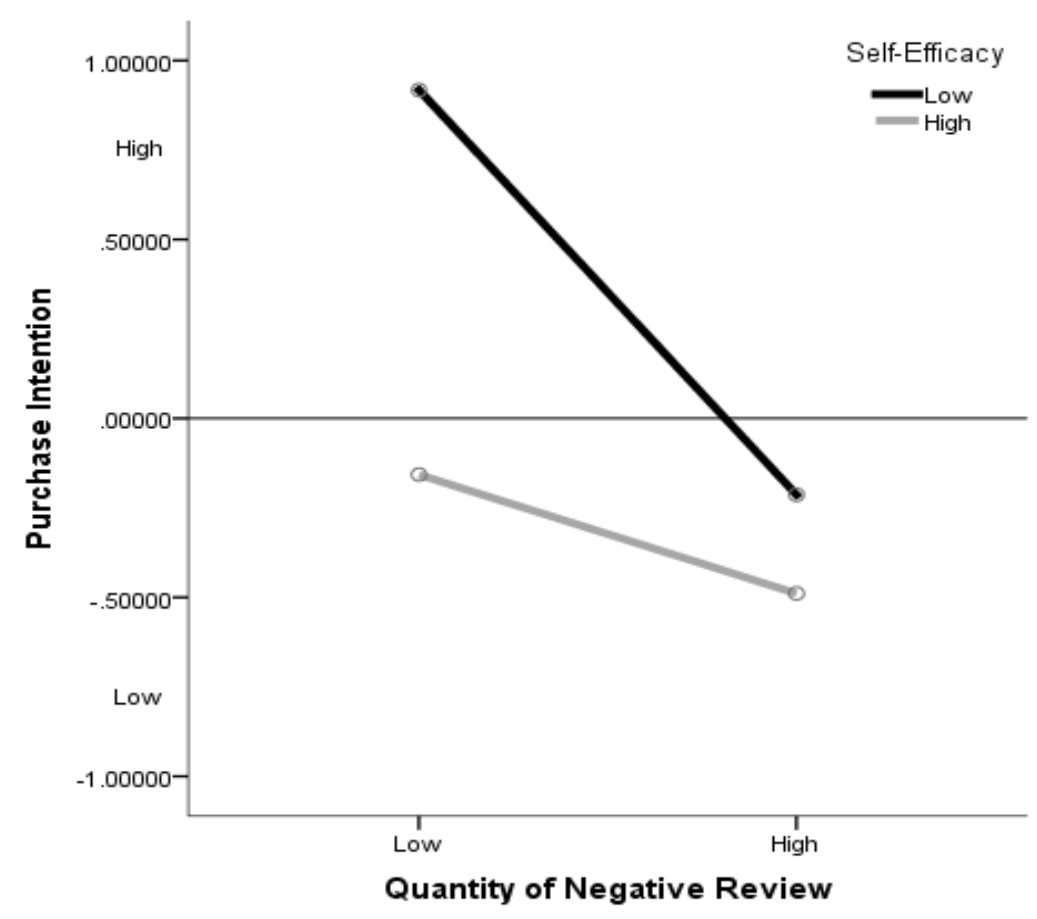

Figure 4. Purchase Intention Impact of Quantity of Negative Review

In Figure 2, interaction effect of self-efficacy and systematic/central factor (quality of negative review) shows the positive moderating role of self-efficacy, and in Figure 3-4, interaction effects of self-efficacy and heuristic/peripheral factors (source credibility and quantity of negative review) demonstrate the negative moderating role of self-efficacy. Hypotheses of H4-H6 are further supported. 


\section{Discussions and Conclusions}

In this paper we provide insights into impact of negative online review on consumer's purchase intention from a dual-process perspective. Specifically, we examine the systematic/central and heuristic/peripheral factors that can affect consumer's purchase intention, and the moderating role of self-efficacy. Our empirical findings support the view that both the systematic/central factor (quality of negative review) and heuristic/peripheral factors (source credibility and quantity of negative review) have significantly negative effect on the purchase intention of consumers, among which the quality of negative review is the most influential factor. In addition, self-efficacy positively moderates the impact of systematic/central factor on consumer's purchase intention and negatively moderates the impact of heuristic/peripheral factors.If the self-efficacy of a consumer is high, he will make decision mainly relying on quality of negative review, while those consumers with low self-efficacy may refer to source credibility and quantity of negative review associated with online review to facilitate their purchase decision-makings.

\subsection{Implications}

The findings of this study not only provide new insights into the impact of negative online review literatures but also generate some practical implications.

(1) Theoretical implications

To simplify research designs, a number of literatures only took positive online review into considerations. This work is designed to investigate the impact of negative online review. We introduce dual-process theory, a general theory on information processingand informational influence, into the context of negative review, and provide research model including systematic/central factor, heuristic/peripheral factors and moderator affecting consumer's purchase intention. We introduce quantity of negative review as a heuristic/peripheral factor, which is empirically examined to be significantly influential on consumer's purchase intention. The characteristic of negative review is much more complex than positive one, and it has different impacts towards different consumers. This work contributes to the literatures by unveiling the roles of different negative review factors at different levels of the consumer's self-efficacy. It is notable that although the impact of quality of negative review is greatest among all factors affecting consumer's purchase intention (quality of review has also been examined as most influential factor in many positive online review context), the impact of quantity of negative review is very close to that of quality of negative review. It shows that in the context of negative online review, the quantity is also an important factor worthy of attention.

\section{(2) Practicalimplications}

Negative review on online shopping website has attracted growing attentions by both online merchants and consumers. As quality of negative review is examined as the strongest determinant of consumer's purchase intention, negative review of high quality with supportive evidence and explanations need to be especially addressed by online merchants. On one hand, to improve the product according to the description of negative review, while on the other hand topost timely and detailedreply and explanation below the negative review may be effective strategies to reduce the negative effects. Because source credibility significantly affects consumer's purchase intention, if consumer with high reputation or ranking posts negative review, responses should be performed with high priority. As quantity of negative review is a concerned factor, online merchants should monitor the quantity and proportion of negative review in time, and make efforts to reduce negative reviews by means of improving product quality, customer care and timely response, as thus to enhance brand's satisfaction and promote product sales. 


\subsection{Limitations and Future Research}

Despite of theoretical and practical implications of this study, there still exist certain limitations.Firstly, the negative reviews adopted are limited to what were read by consumers on online shopping websites. There are some professional third-party online review platforms (e.g., Epinions.com, Dianping.com) with a huge number of online product reviews, andthe generalizability of our findings to the context of third-party online review platforms needs to be examined. Besides, the influence of different cultural backgrounds, control variables, and product types are to be considered. Secondly, the research model explains $59.4 \%$ of variances in purchase intention, which suggests some unveiled important predictors exist. The missing factors may include perceived ease of use of online review system, consistency of negative online reviews, etc. Therefore, a better explanatory research model incorporating more important factorscan be expected. Finally, as measurement performed in this study is based on respondents' self-reporting recall of recently read negative review, the objectivity and accuracy need to be improved in future studies.

\section{Conclusions}

Online review is an important form of user-generated-content, and provides helpful information for consumer's online purchase decision. Negative online reviews deserve special attention due to their stronger effects on consumers' behaviors and product sales than positive ones. This study investigates the systematic/central factor as quality of negative review and heuristic/peripheral factors as source credibility and quantity of negative review essential to drive consumer's purchase intention, from a perspective of dual-process theory.It is verified that consumer's self-efficacy plays a moderating role affecting dual-process factors being adopted. We expect the findings of this work can both theoretically supplement extant negative online review literatures and practically provide feasible implications for online consumers and merchants to better process online reviews, improve online view systems, and build brands.

\section{Acknowledgements}

I would highly appreciate the editors andanonymous reviewers for their constructivecomments for improving the manuscript.This work is supported by the National Natural ScienceFoundation Program of China (NSFC) (Grant No. 71361011).

\section{Appendix}

A. Measurements of constructs

\begin{tabular}{ll}
\hline Construct & Item \\
\hline Quality of Negative & (Adapted from Zhang, 1996; Zhang 2014) \\
Reviews & 1. This review arguments are strong. \\
& 2. This review arguments are persuasive. \\
& 3. This review provide sufficient information about the goods. \\
& 4. This review provide timely information about the goods. \\
\hline Source Credibility & (Adapted from Berlo, 1969; Zhang, 2014) \\
& $\begin{array}{l}\text { 1. People who left this review is knowledgeable. } \\
\text { 2. People who left this review is expert. }\end{array}$ \\
& $\begin{array}{l}\text { 3. People who left this review is highly rated in the website. } \\
\text { 4. People who left this review is trustworthy. }\end{array}$ \\
\hline Quantity of Negative & 1. There exist many similar negative reviews about the product. \\
Reviews & 2. To what extent do you perceive the proportion of negative reviews about the \\
product. & 3. Many people posted negative review about the product. \\
\hline Expertise & (Adapted from Sussman, 2003) \\
& 1. How informed are you on the subject matter of this review. \\
\hline
\end{tabular}




\begin{tabular}{ll}
\hline & 2. To what extent are you an expert on this review topic. \\
3. To what extent are you knowledge on this review topic. \\
\hline Involvement & (Adapted from Zhang, 2004) \\
& 1. I was greatly involved in the topic of this review. \\
& 2. It was important for me to get information from this review. \\
3. I am interested in this review topic. \\
\hline Puchase Intention & (Adapted from Gilly, 1998) \\
& 1. I intend to buy the product. \\
2. I am interestedin the product. \\
3. I will buy this product in priority among similar products.
\end{tabular}

\section{References}

[1] P. F. Bone, "Word-of-mouth effects on short-term and long-term product judgments", Journal Business Research, vol. 32, no. 3, (1995), pp. 213-223.

[2] H. Oh, A. Animesh and A. Pinsonneault, "Free versus for-a-fee: the impact of a paywall on the pattern and effectiveness of word-of-mouth via social media", MIS Quarterly, vol. 40, no. 1, (2016), pp. 31-56.

[3] C. Dellarocas, "The digitization of word of mouth: promise and challenges of online feedback mechanisms", Management Science, vol. 49, no. 10, (2003), pp. 1407-1424.

[4] E. Lee and S. Y. Shin, "When do consumers buy online product reviews? Effects of review quality, product type, and reviewer's photo", Computers in Human Behavior, vol. 31, no. 1, (2014), pp. 356-366.

[5] G. Gao, B. N. Greenwood and R. Agarwal, "Vocal minority and silent majority: how do online rating reflect population perceptions of quality”, MIS Quarterly, vol. 39, no. 3, (2015), pp. 565-589.

[6] J. Berger, A. T. Sorensen and S. J. Rasmussen, "Positive effects of negative publicity: When negative reviews increase sales", Marketing Science, vol. 29, no. 5, (2010), pp. 815-827.

[7] N. Hu, N. S. Koh and S. K. Reddy, "Ratings lead you to product, reviews help you clinch it? The mediating role of online review sentiments on product sales", Decision Support Systems, vol. 57, no. 1, (2014), pp. 42-53.

[8] C. M. K. Cheung and D. R. Thadani, "The impact of electronic word-of-mouth communication: a literature analysis and integrative model", Decision Support Systems, vol. 54, no. 1, (2012), pp. 461-470.

[9] P. M. Herr, F. R. Kardes and J. Kim, "The effects of word-of-mouth and product-attribute information on persuasion: an accessibility diagnosticity perspective", Journal of Consumer Research, vol. 17, no. 4, (1991), pp. 454-462.

[10] C. Park and T. Lee, "Information direction, website reputation and eWOM effect: A moderating role of product type", Journal of Business Research, vol. 62, no. 1, (2009), pp. 61-67.

[11] R. Ahluwalia, R. E. Burnkrant and H. R. Unnava, "Consumer response to negative publicity: The moderate role of commitment. Journal of Marketing Research, vol. 37, no. 2, (2000), pp. 203-214.

[12] S. M. Mudambi and D. Schuff, "What makes a helpful online review? A study of customer reviews on amazon.com", MIS Quarterly, vol. 34, no. 1, (2010), pp. 185-200.

[13] K. Z. K. Zhang, S. J. Zhao and C. M. K. Cheung, "Examining the influence of online reviews on consumers'decision-making: A heuristic-systematic model”, Decision Support Systems, vol. 67, (2014), pp. 78-89.

[14] K. B. Yap, B. Soetarto and J. C. Sweeney, "The relationship between electronic word-of-mouth motivations and message characteristics: The sender's perspective", Australasian Marketing Journal, vol. 21, no. 1, (2013), pp. 66-74.

[15] R. Decker and M. Trusov, "Estimating aggregate consumer preferences from online product reviews", International Journal of Research in Marketing, vol. 27, no. 4, (2010), pp. 293-307.

[16] N. Hu, L. Liu and V. Sambamurthy, "Fraud detection in online consumer reviews", Decision Support Systems, vol. 50, no. 3, (2011), pp. 614-626.

[17] Y. Pan and J. Q. Zhang, "Born unequal: A study of the helpfulness of user-generated product reviews", Journal of Retailing, vol. 87, no. 4, (2011), pp. 598-612.

[18] Z. Chen and N. H. Lurie, "Temporal contiguity and negativity bias in the impact of online word-of-mouth”, Journal of Marketing Research, vol. 50, no. 4, (2013), pp. 463-476.

[19] S. Ludwig, K. de Ruyter and M. Friedman, "More than words: The influence of affective content and linguistic style matches in online reviews on conversion rates", Journal of Marketing, vol. 77, no. 1, (2013), pp. 87-103.

[20] R.W. Naylor, C. P. Lamberton and D. A. Norton, "Seeing ourselves in others: Reviewer ambiguity, egocentric anchoring, and persuasion", Journal of Marketing Research, vol. 48, no. 3, (2011), pp. 617-631.

[21] N. Hu, L. Liu and J. J. Zhang, "Do online reviews affect product sales? The role of reviewer characteristics and temporal effects", Information Technology and Management, vol. 9, no. 3, (2008), pp. 201-214.

[22] D. Godes and D. Mayzlin, "Firm- created word-of-mouth communication: Evidence from a field test, Marketing Science, vol. 28, no. 4, (2009), pp. 721-739. 
[23] J. A. Chevalier and D. Mayzlin, "The effect of word of mouth on sales: Online book review", Journal of Marketing Research, vol. 43, no. 3, (2006), pp. 345-354.

[24] H. H. Chang and L. H. Wu, "An examination of negative e-WOM adoption: brand commitment as moderator", Decision Support Systems, vol. 59, (2014), pp. 206-218.

[25] J. Ward and A. Ostrom, "Complaining to the masses: the role of protest framing in customer- created complaint web sites", Journal of Consumer Research, vol. 33, no. 2, (2006), pp. 220-230.

[26] I. M. Wetzer, M. Zeelenberg and R. Pieters, "Never eat in that restaurant, I did!": exploring why people engage in negative word-of-mouth communication", Psychology \& Marketing, vol. 24, no. 8, (2007), pp. 661-680.

[27] D. Godes and J. C. Silva, "Sequential and temporal dynamics of online opinion", Marketing Science, vol. 31, no. 3, (2012), pp. 448-473.

[28] W. W. Moe, "Online product opinions: Incidence, evaluation and evolution”, Marketing Science, vol. 31, no. 3, (2012), pp. 372-386.

[29] Y. Zhao and S. Yang, "Modeling consumer learning from online product reviews", Marketing Science, vol. 32, no. 1, (2013), pp. 153-169.

[30] H. H. Chang, Y. C. Tsai and K.H., Wong, "The effects of response strategies and severity of failure on consumer attribution with regard to negative word-of-mouth", Decision Support Systems, vol. 71, (2015), pp. 48-61.

[31] S. Chaiken, "Heuristic versus systematic information processing and the use of source versus message cues in persuasion", Journal of Personality and Social Psychology, vol. 39, no. 5, (1980), pp. 752-766.

[32] R. E., Petty and J. T. Cacioppo, "The elaboration likelihood model of persuasion", Advances in Experimental Social Psychology, vol. 19, (1986), pp. 123-205.

[33] A. H. Eagly and S. Chaiken, "The Psychology of Attitudes, Harcourt Brace Jovanovich College Publishers", Fort Worth, TX, (1993).

[34] A. Bhattacherjee and C. Sanford, "Influence process for information technology acceptance: an elaboration likelihood model”, MIS Quarterly, vol. 30, no. 4, (2006), pp. 805-825.

[35] D. H. Park, J. Lee and I. Han, "The effect of on-line consumer reviews on consumer purchasing intention: the moderating role of involvement", International Journal of Electronic Commerce, vol. 11, no. 4, (2007), pp. 125-148.

[36] W. Zhang and S. Watts, "Capitalizing on content: information adoption in two online communities", Journal of the Association for Information Systems, vol. 9, no. 2, (2008), pp. 73-94.

[37] D. V. Thompson and P. Malaviya, "Consumer-generated ads: Does awareness of advertising co-creation help or hurt persuasion?", Journal of Marketing, vol. 77, no. 3, (2013), pp. 33-47.

[38] A. Todorov, S. Chaiken and M. D. Henderson, "The heuristic-systematic model of social information processing”, in: J.P. Dillard, M. Pfau (Eds.), The Persuasion Handbook: Developments in Theory and Practice, Sage Publications, Thousand Oaks, CA, (2002), pp. 195-212.

[39] S. Chen and S. Chaiken, "The heuristic-systematic model in its broader context, in: Chaiken S., Trope Y. (Eds.), Dual-Process Theories in Social Psychology, Guilford Press, New York, NY, US, (1999), pp. 73-96.

[40] M. D. Slater and D. Rouner, "How message evaluation and source attributes may influence credibility assessment and belief change", Journalism \& Mass Communication Quaterly, (1996), pp. 974-991.

[41] C. Ferran and S. Watts, "Videoconferencing in the field: a heuristic processing model", Management Science, vol. 54, no. 9, (2008), pp. 1565-1578.

[42] R. E. Petty and J. T. Cacioppo, "Attitudes and persuasion: Classic and contemporary approach, Dubuque, IA: William C. Brown, (1981).

[43] S. W. Sussman and W. S. Siegal, "Informational influence in organizations: An integrated approach to knowledge adoption”, Information Systems Research, vol. 14, no. 1, (2003), pp. 49-65.

[44] R. H. Ducoffe, "Advertising value and advertising the web", Journal of Advertising Research, vol. 36, no. 5 , (1996), pp. 21-35.

[45] K. Y. Tam and S. Y. Ho, "Web personalization as a persuasion strategy: an elaboration likelihood model perspective", Information Systems Research, vol. 16, no. 3, (2005), pp. 271-291.

[46] G. Bohner, G. B. Moskowitz and S. Chaiken, "The interplay of heuristic and systematic processing of social information", European Review of Social Psychology, vol. 6, no. 1, (1995), pp.1 33-68.

[47] C. Pornpitakpan The persuasiveness of source credibility: a critical review of five decades' evidence. Journal of Applied Psychology, vol. 34, no. 2, (2004), pp. 243-281.

[48] D. H. Park and J. Lee, "eWOM overload and its effect on consumer behavioral intention depending on consumer involvement", Electronic Commerce Research and Applications, vol. 7, no. 4, (2008), pp. 386-398.

[49] P. J. Sher and S. H. Lee, "Consumer skepticism and online reviews: an elaboration likelihood model perspective", Social Behavior and Personality: An International Journal, vol. 37, no. 1, (2009), pp. 137-143.

[50] R. E. Petty and D. T. Wegener, "The elaboration likelihood model: Current status and controversies, in dual-process theories in social psychology”, New York: Guilford Press, (1999), pp. 41-72. 
[51] G. M. Marakas, R. D Johnson and P. F. Clay, "The evolving nature of the computer self-efficacy construct: An empirical investigation of measurement construction, reliability and stability over time", Journal of Association for Information Systems, vol. 8, no. 1, (2007), pp. 16-46.

[52] Y. Zhang Responses to humorous advertising: The moderating effect of need for cognition. The Journal of Advertising, vol. 25, no. 1, (1996), pp. 15-31.

[53] D. K. Berlo, J. B. Lemert and R. J. Mertz, "Dimensions from evaluating the acceptability of message sources”, Public Opinion Quarterly, vol. 33, no. 4, (1969), pp. 563-76.

[54] W. Zhang and S. Watts, "Knowledge adoption in online communities of practice", Revue S.I.M., vol. 9, no. 1, (2004), pp. 81-102.

[55] M. C. Gilly, J. L. Graham and M. F. Wolfmbarger, "A Dyadic Study of Interpersonal Information Search", Academy of Marketing Science, vol. 26, no. 2, (1998), pp. 83-100.

\section{Author}

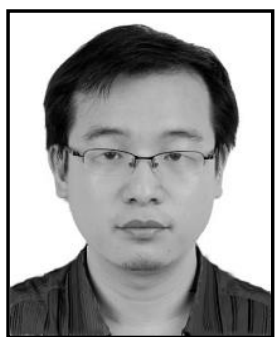

Quan Xiao, received his Ph.D. degree in management science and engineering from Huazhong University of Science and Technology, China in 2010 . He is currently a lecturer in the School of Information Technology, Jiangxi University of Finance and Economics, China.His research interests include decision support systems, risk identification and online customer behaviors. 